\title{
Historicity and historiography of being-a-nursing- student in the construction of care in Heidegger
}

\author{
Silvana Silveira Kempfer, Telma Elisa Carraro, Marta Lenise do Prado \\ Federal University of Santa Catarina, Santa Catarina, Brazil \\ Correspondence: Silvana Silveira Kempfer. Address: Street Jau Guedes da Fonseca, 292 ap 101 B, Florianópolis, Santa \\ Catarina, Brazil. Email: silvanakempfer@yahoo.com.br
}

Received: October 7, 2013

Accepted: March 6, 2014

Online Published: April 24, 2014

DOI : $10.5430 /$ jha.v3n5p88

URL: http://dx.doi.org/10.5430/jha.v3n5p88

\section{Abstract}

Objective: Reveal the experience of being-a-nursing-student as it relates to care.

Method: Phenomenological qualitative research. Data were collected in March and May, 2011 by interviewing seven nursing students at the Federal University of Santa Catarina. The interviews were analyzed using heideggerian hermeneutics in three steps: Pre-comprehension, comprehension, and the interpretation of the participants' responses.

Results: Reflecting on the historiographical context of being-a-nursing-student, the respondents realized that they are immersed in the family context throughout their career, and described their experiences as temporal discoveries in their life. By unveiling their historicity in the phenomenon of care, the students were able to recognize themselves in this process, interacting with each other and with the practical situations in which moments of care were required. This process has made it possible to conceive a vision of care from their past experience.

Conclusion: To nursing students, one concept of care involves reflecting continuously on oneself and on the other.

\section{Key words}

Nursing students, Nursing cares, Family connections, Nursing philosophy

\section{I ntroduction}

All beings have their own history individual, collective, social, cultural or academic. Building their life involves connecting moments with experiences in a movement of meaning in their existence in time. Martin Heidegger was most important theorist on issues of being and time in the 20th century. He created a specific language to explain these concepts.

Among his many phenomenological contributions, he opened up new ways of comprehending being and time rediscovering such thinking during specific historical period in which Germany society was centred in economic development and individual experiences were less valued. Heidegger brought out important philosophical questions; to him, time is the phenomenon that permits the comprehension and interpretation implicit in being. He said that the sense of being is time, in other words, the role of thinking is to make the human being sensible to the passage of time ${ }^{[1]}$.

As an existentialist, Heidegger addresses questions about being in the world- in other words, being in relationships, in taking care and, in concern. To him “ since being-in-the-world is essentially care, being-together-with things at hand could 
be taken in our previous analyses as taking care of them, being with the being-with others encountered within the world as concern” ${ }^{22]}$. The being reveals itself to the world by making its way, and, in this sense, Heidegger mentions that this is the mode in which exists in the world; to him, the human condition concern which is experienced temporality ${ }^{[1]}$.

Reflecting on being-a-nursing-student on the occupation of caregiver involves knowing one's history of life and one's conceptions about care, and recognizing this relationship as important to one's professional nursing practice in the future. The being who assumes his/her condition of being-in-the-world is in a historical condition. History here takes the sense of life, to Heidegger "the analysis of the historicity of existence attempted to show that this being is not temporal, because it is in history, but because, on the contrary, it exists and can exist historically only because it is temporal in the ground of its being” ${ }^{[2]}$. Heidegger also understands historicity as a possibility of existence, and historiography as a register of the process of life.

Nursing is a profession essentially of care, and the being-a-nursing-student means being to care. The historical aspects of being-a-nursing-student have the connotation of culture, tradition and family, where students summarize their experiences using their past experiences of caring and being care for to construct new ones. They need to consider carefully the intrinsic condition of being human, and to understand it is not possible to think about care as just theorizing about action ${ }^{[3]}$.

Given this context, the following question emerges from this study: How the being-a-nursing-student experiences care throughout his life? The question indicates to the research objective: reveal the experience of being-a-nursing-student as it relates to care.

\section{Methodology}

It was conducted a phenomenological study that used the theoretical framework of Heidegger ${ }^{[2,4]}$. The data analysis was done following the hermeneutic perspective steps, which is characterized by pre-comprehension, comprehension, and interpretation of the phenomenon. Phenomenology is "hermeneutics in the original signification of that word, which designates the work of interpretation" ${ }^{[2]}$.

The participants of the study were seven students enrolled in the second year of the Nursing course of the Federal University of Santa Catarina - Brazil. The data collection occurred between March and May 2011, through phenomenological interview in a private classroom.

The phenomenological interview investigated how the being-a-nursing-student experiences care throughout his life? The interview was recorded and transcribed after read repeatedly; the reports indicated the understanding and interpretation of the phenomenon.

The study complied the requirements of the Resolution 196/96 ${ }^{[5]}$, which deals with researches on human beings in Brazil, and was approved by the ethics committee of the university. Participants were identified with an alphanumeric code to ensure anonymity (A1, A2, A3...) described immediately after the responses.

\section{Results}

\subsection{Historiographical conceptions of care, culture and tradition in the family care}

The historiographical aspects had been revealed by being-a-nursing-student in two ways: when they described the experiences that happened in the past; and when, from this description, they reflected on these experiences, bringing them back to their conscience today. These two moments are described in this study as historiography, because they determine the temporal experiences on history, to reflect and make the experience an experience. 
Memories are always events in the past that come to mind in movement, and are described by Heidegger as recapture. For the author, "the recapture that reveals to the presence its own history" ${ }^{[2]}$. During this movement of recapture, the nursing student reflected about care situations experienced in the past. When they reported the experiences of care that they are aware of, the subjects described the family as primary caregivers: The first memory I have is care in childhood with my grandparents. I lived with my parents, but my grandparents were all day with me, my grandmother was like my mother, and my grandfather and my father, and since that time I realized that they were very special to me, and I to them (A7). This perception was similarly described by another being-a-nursing-student: The first perception of care that I have, always until now, is the mother is taking care of the child, the first thing that comes into my head during my life (A6).

Caring is a human condition which exists in personal and professional life. To Heidegger, caring is concern and he poses the question "what is care if not bringing the human being back to its essence?" ${ }^{[6]}$. Caring is also the element that allows the beings to live their historicity, approaching them to their existential condition.

Traditional aspects are unveiled and involve the care in the family. In this sense, Heidegger says that history does not mean just past, or what was passed, but also the transformations in the human being on their cultural and traditional aspects on time. For him, historical aspects are traditional legacies, recognized with historiographical or evident ${ }^{[2]}$. There were situations described by nursing students related to their families, especially to their mother and the grandmother. They used to told them about the situations which they have in their memories and these reports reflected temporally and were assimilated by them: My birth was the first care I received, that fragile little baby and mother. [...] At first I thought it was in the family, in the care of my mother, she always stayed home. After a while I was grown, had three years and she started working (A3). To another nursing student, the earliest memory of care was: especially my grandmother and my mother say that when I was a baby, I do not know exactly why, but I cried a lot at night. My grandmother sometimes had to sing church songs to calm me down, once I slept between my mother and my father to sing and soothe me (A1).

Besides the mentioned mother and grandparents' care, they also remembered their relationship with brothers, describing moments of care in childhood: Disregarding the principle that maternal bond, the first vision care I have it on pre-school, my brother and I [...]. The people going down the street to school stood a mile away, we went walking, this is the first view I have (A5). In another report, taking of siblings was experienced as task: When I was 12, my father started working out, and my brother was younger and I had to take care of him. Was to blame, I was a child of 12 years and cooked for him. I remember we got home, I did things, and sometimes annoyed and thought how he sees me handle it, I have to take care of him and I cannot do my thing. And I was taking care of him until I was about 16 years (A7). Another experience of care was described as unpleasant, because it took away the freedom to live differently, as described: I remember the first experience of care that comes in mind is about my brother because my mother and father always worked horrors, and I always stayed with my brother, he is three years younger than me. Moments that had cared enough of it (A2).

The cultural aspects expressed by the being-a-nursing-student revealed situations in which he/she observes professional care, and from that he/she realizes that needs to learn more details about health to take care of another person. The care is linked to the presence of a health problem as mentioned: Then there was another time that I became a caregiver, was when my sister opened the refrigerator, dropped a plate of glass and cut her foot, I think it took a little vase, not known, and bleeding heavily, I do not know how I managed to take care of her, because she did not like, was afraid of blood, of these things (A6).

As time goes by, the being-a-nursing-student experienced care as something outside themselves, which involves an action, an intervention, and a practice that is linked to the gesture of care, now described as the care of others: My grandfather was hit and stayed four years at home, in bed, and had to bathe, change diapers, make the dressing, was a complex care. In the beginning there were only the fractures, then he started giving trouble regarding breathing, stomach, and the lesions began to spread. At that time I remember that I was pulled back home, I was young, I was 12, studied and helped as I could (A1). I was on the side of my grandparents' house [...]. There were several things and have always been there, going every day to 
see how they were and tried to be around to care a little, or to assist in something (A2). The friends were also mentioned in moments of care, as reported: I was always careful with my friends, since childhood I had friends (A5).

The experiences were described in different ways over time, and brought new opportunities of immersion in the being-a-nursing-student historicity. Their description goes on to consider other elements in the context of care: My vision care was reversed this time, because it was my mother who took care of me, and if so, was that I was taking care of her, me and my brother. We had to take care of the house, had to keep an eye on my sister had to take care of her, had to see if the parent was feeding well. My father was in the hospital with my mother, but he had to work, so I had to go to the hospital to take care of her, had to stay there and see how were the exams. It was a tough time, and this vision was my first contact with the hospital (A5).

In this historiographical context, the being-a-nursing-student described their care experiences from two aspects: one that arises while they were receiving care, and another as a caregiver. These reflections give opportunity to another perspective, in which care becomes a condition that involves a relationship of interaction between the caregiver and the care: I met my friends from college, five girls, we take care of each other, we know each other, and as you study the same thing in the same area, we talked a lot about caring, caring about giving (A4). Another nursing student said: For all that I would make a plan, a line that would be my family. From birth to today, my family takes care of me, we take care, care at all times (A5).

The human being lives on a continuum movement of veiling and unveiling. By reflecting on the historiographical context of being-a-nursing-student they realized that they were immersed in a family context throughout their career. They described their experiences as temporally unveiled and opened new possibilities to insert their friends, neighbors and classmates in their care context.

\subsection{Historicity of the being-a-nursing-student and care: establishing conceptual relations}

The being-a-nursing-student in the context of historicity was in a learning process of care, and experienced this phenomenon in his/her history. When he/she described the situations of care, the being-a-nursing-student was in the process of recalling his/hers experiences and building his/hers own ways from that. This scenario was composed by values, beliefs, lived situations which emerged beyond the care practices and subjective situations that influenced his/hers thinking. Kleiman used an example mentioned by Heidegger about learning: when an carpenter apprentice learns how to build a piece of furniture under the guidance of his master, he is not only learning to select the tools needed to carve the wood, but also learning about the hidden potential of the wood and it is possibilities of becoming furniture ${ }^{[7]}$.

The experiences so far described by being-a-nursing-student related about care were configured in the past and allowed a new comprehension of those moments in a historical past. Those historical moments were revisited by conscience and took on new dimensions and opened new possibilities to interpret his/her own history. To Heidegger, presence meant being there, in other words, being released in world and on time ${ }^{[2]}$.

In reflecting about the care, the being-a-nursing-student establishes a link with what means care for him/herself and approaches it from him/her experience, and then interprets these experiences historically, i.e., this conscience of the experience of care is unveiled by the language: I have good experiences, I have always been well cared for by my family (A4). [...] There are many experiences, has the experience of learning, the experience of teaching, to respect the opinions of others, these are the experiences that I bring in attention when the person is sick. Although sick, is there, then not only be talking, I think it's the responsibility with the sick person (A1).

This unveiling was considered by Heidegger as authenticity, i.e., the being is in the world by two forms: the proper and the improper. The proper or authentic is when the being reflects about his/her life significantly. The improper or inauthentic is when the being lives just his/her everydayness without reflection. 
It is important to emphasize that the care is thought as authentically existential essence of being human and concerns zeal, devotion, attention, good treatment, constituting thereby a foundation through which the person leaves his/herself to focus the concern for the other ${ }^{[8]}$.

Considering the being-a-nursing-student historically in his/her academic experience in a nursing program, he/she has previous expertise related to the tradition and beliefs of care. He/she will construct his/her trajectory in this period of training, from the interaction with the people involved in this context ${ }^{[9]}$.

Remembering their experiences of care linked to culture and tradition enables the emersion of feelings, sensations and behaviors manifested historically, as in the speech: The care involves not only what I feel, or what the other person feels, but what all that person had during her life, because I think the time of childhood, adolescence, and everything, everything will reflect the care, professional care to the patient, and the patient with the professional care and even between family, among people who do well, and friends. I think the care is not only the hospital, but the care that you have with people you like, and even careful with whom you do not like, or do not know, because all this will form a great care and exchange experience, this exchange of experience, what form will not only change the person you cared, but it changes you (A7).

By becoming aware of care in his/her life, the being-a-nursing-student sees situations in which he/she is immersed, not objectively, but subjectively in various historical moments. The remembrance is not a correlate observation of theoreticalhistorical aspects, but the inseparable content of the existence in conformity with the occurrence on the time and it is called the authentic historicity of the being ${ }^{[2]}$. "Authentic historicity understands history as the recurrence of what is possible and knows that a possibility recurs only when existence is open for it fatefully" ${ }^{[2]}$.

The care experienced in different ways of the being-a-nursing-student is unveiled here on the soil of tradition and culture. Demonstrations of care during childhood by his/her family were revealed as affective care dedicated to values and beliefs, as means of care for each other. This care is described as being sentimental-academic, when he/she says: [...] this is something sentimental instinct, something that seems part of the human race seems to be built, we are, is instinctive, that's right, you have to give a hug, knowing that someone is crying and wanting to accommodate a person crying on your side makes you feel bad, you move (A5). This being-a-nursing-student otherwise describes nursing care, which calls for professional care, according to the report: [...] and takes care professional which is the material that is the part that I have, be aware what I'm doing, I have to take a CPR so, for what, I do not even have affection for that person, knowing the pathological condition of it, these spheres intersect and give this special feature, this is my vision of what is care (A5).

The professional care described by the being-a-nursing-student is linked to nursing care as part of the theoretical and practical actions of doing an occupation, not only as a technique or procedure but, as an intentional choice of being in the care process. This approaches to the thinking of Graçase Santos ${ }^{[10]}$, when they understand that Nursing has understood the being in a more widely way, where the being is not only a receiver far from an ethical and existential sense.

By observing historically the concept of care, it is possible to see the bond with family, society, culture, technics and other aspects that can make the evolution over time. It is also possible to say that care has a pre-professional and a professional step. In this regard, the modes of care have their values and feelings linked to their corresponding stratum, tribal, family or profession $^{[11]}$.

The care is revealed by being-a-nursing-student as intrinsic to human life, as a dimension that they experience with the others and cannot be simply quantified or objectified, but it must be felt to be part of experiences, as described: care is something you need to feel and does not explain, is a little faith, you believe, do not see but still believe in him. This is my current vision of care, is essential for life, as well as oxygen, water, how to eat, how to love, how to be angry, how to hate, be careful, be careful is a key issue for all and lifelong (A5). 
To manifest his/herself as a being-for-care, the being-a-nursing-student shows as authentic his/her historical experience, and demonstrates self-reflection and self-conscience, described in the reports: in addition to the care to be an individual act, it is also a reciprocal act, we have to give our professional side, but we also have to be sensitive (A6).

This sensitivity to care described by the being-a-nursing-student is also part of their everyday life in Nursing in their professional practice. But beware the body has been the focus of nursing, this cannot be the only perspective, as highlighted Hernandez et al ${ }^{[12]}$. They identified that nursing care is currently related to prevention and care, paying no attention to the phenomenon that occurs in an authentic moment between professional and patient. In this sense, the being-a-nursing-student described: care for me is not just a little slash, is not only clean, is careful to feeling, to support a person, help a person, it is even greater care than a nursing technique, care for me is different (A4).

To unveil the phenomenon of care, the being-a-nursing-student observes that the first description is linked to the factual and objective experience that happened in his/her in the past, but then goes on to consider the subjective aspects, and from this they interpret the previous experience. Heidegger mentions that the facticity becomes decisive to the factual own life experience, i.e., the everyday experience considers the situation spiritual-historical of being as responsible for conducting the fundamental experience that emerges from that experience in historicity ${ }^{[2]}$.

The practical aspects of nursing care, which constitute the factual experience, are important to the development of the student in their profession. This kind of thinking is necessary for the acquisition of technical knowledge and practical skills essential for nursing education. However, nursing profession requires more than calculations, scientific and technical knowledge ${ }^{[7]}$.

In a phenomenological study of the meaning of care and care for nurses, Gamboa ${ }^{[13]}$ found several publications on what nurses think about care, and identified a number of behaviors and attitudes somewhat common in all studies. Some consider care as part of human nature, others as a feeling, an emotion, or as a therapeutic intervention, such as a traditional form of science. When a theorist exposes his/hers ideas about care, also assumes the position of a caregiver, revealing and printing different meanings for the phenomenon, based on their experiences and culture.

In another study developed with nursing faculty, Vale; Pagliuca ${ }^{[8]}$ constructed a collective concept of care as "an intentional phenomenon, essential to life, occurring in the encounter of human beings interacting through actions involving conscience, diligence, solidarity and love" ${ }^{[8]}$. This concept is related to the care mentioned until here by being-a-nursing-students.

By unveiling his/her historicity in the phenomenon of care, the being-a-nursing-student demonstrates to recognize his/herself in this process, interacting with each other and with the practical situations of care enabling to conceive a vision of care from their past experiences.

The conceptions of care that were described are related to an authentic care where the elements are manifested in the presence (Dasein), revealing the being-a-nursing-student as a being wrapped in their tradition and culture.

\section{Conclusion}

Unveiling the meaning of care to being-a-nursing-student following the design of pre-comprehension, comprehension and interpretation is not separated, but in continuous motion. The pre-comprehension consists of the appropriation of the concepts and the resumption or recollection of their experiences of care; comprehension is characterized in this study as the time the being-student historiography assumes his/her position, that is, it is able to from his memories, constitute the record of their experiences: historiographical conceptions of care-culture and tradition in family care. Finally, the interpretation is when understands themselves as being-in-the-world and, from this, takes care of his concepts as a being itself, being here: Historicity of being-a-nursing-student and care - establishing conceptual relations. 
When we began this study in seeking to reveal the phenomenon of care to be-in the student perspective of heideggerian hermeneutics, it was not possible to conceive the complexity of reflection and its nuances. In the first movement hermeneutic pre-comprehension, the approach of the subjects involved and occurred earlier perceptions of care were placed, the factual experience, i.e., the everyday aspects known about the phenomenon emerged, enabling constitute the first stage of care, which is tied to the family.

When conducting the second time hermeneutical reflection, consisting of comprehension, here called historiography, new elements have emerged on care context, and situations were described in more detail. The care taken broad connotation involving, in addition the family, friends, colleagues, other scenarios beyond his personal life, such as the hospital and the university itself. The understanding of the be-careful scholar was an interesting time; here had to dip into their memories and revisit situations experienced. This resumption revealed experiences that shaped care for this be-student.

The interpretation of being-a-nursing-student care on the phenomenon characterizes the third hermeneutic moment, here described as historicity, where the being, from its conception prior to his understanding, shall constitute what may be called experience, i.e., to interpret their historical experience, conceives his care concepts, which are characterized as soil their future personal and professional conduct.

Caring for the being-a-nursing-student involves a historic building linked the family tradition and culture, which over the years has been appropriating various forms. Concern involves the relationship be-be-caregiver and care. Is linked to their moral and ethical, in which care is live and continually reflect on themselves and others.

This study suggests an approach, at first glance, this naive world of being-a-nursing-student and he expressed as carefully considering this phenomenon to the being-a-nursing-student in a continuous motion veiling and unveiling. However, power to bring out aspects of their perception and vague median gives us authentically understand the concepts of future care professional.

\section{References}

[1] Safranski R. Martin Heidegger, Between Good and Evil. United States of America: President and Fellows of Harvard College. Second printing. 1998. PMid: 9788745.

[2] Heidegger M. Being and Time. New York: State University of New York Press. 1996.

[3] Oliveira MFV; Carraro TE. Care in Heidegger: an ontological possibility for nursing. Rev Bras Enferm. Brasília. 2011; 64(2): 376-80.

[4] Heidegger M. Wegmarken. GA, Band 9. Frankfurt: Vittorio Klostermann. 1976.

[5] Brazil. National Health Council. Resolution 196/96. Regulatory Guidelines and Standards for Research Involving Being Humans. Available from: http://www.conselho.saude.gov.br/resolucoes/reso_96.htm. Accessed: 15 Out 2010.

[6] Heidegger M. Letter on Humanism. Edinburgh: Edinburg University Press. 2000. PMid: 10731035.

[7] Kleiman S. On the way to learning. Medsurg Nurs. 2009; 18(1): 33-37. PMid: 19331298.

[8] Vale EG, Pagliuca LMF. Construction of a nursing care concept: contribution for undergraduate nursing education. Rev Bras Enferm. Brasília. 2011; 64(1): 106-13.

[9] Costa CR, Fontoura EG, Servo MLS. The meaning of caring/care under the view of the nursing students. Journal of Nursing UFPE [Internet]. 6(1): 149-55. Available from: http://www.revista.ufpe.br/revistaenfermagem/index.php/revista/article/viewArticle/2095. Accessed: 15 Mar 2012. http://dx.doi.org/10.5205/01012007

[10] Graças EM, Santos GF. Nursing care methodology in the phenomenological approach. Rev Esc Enferm USP. 2009; $43(1): 200-7$. PMid: 19437873. http://dx.doi.org/10.1590/S0080-62342009000100026

[11] González JS, Ruiz MCS. Cultural history and aesthetics of nursing care. Rev. Latino-Am. Enfermagem. [Internet]. 19(5). Available from: http://www.eerp.usp.br/rlae. Accessed: 13 Mar 2012.

[12] Hernández MLG, Becerril LC, Goméz BA, Rojas AM, Ortega YH, Martinez CS. Emerging Concept Construction: Professional Nursing Care. Texto Contexto Enferm. 2011; 20(esp): 74-80.

[13] Gamboa NSG. Looking for way to investigate the care. In: The art and science of caring. Bogotá: Ed. Guadalupe. 2006. 